\title{
Yaşam Kalitesi Çalışmalarının Kırsal Kalkınma İle İlişkisi Üzerine Bir Değerlendirme
}

\author{
Hatice Kübra Temiz ${ }^{1}$ \\ ORCID: 0000-0002-6307-6534
}

\author{
Sevinç Bahar Yenigül 2 \\ ORCID: 0000-0002-4310-5369
}

Öz

Kent ve kır bağlamında artan sorunlara yönelik çözüm arayışlarında kır lehinde kırsal kalkınma çabaları ile çözümler yaratılmaya çalışılmıştır. Ancak bu çabaların günümüz koşullarında yeterli sonuçlar vermediğ $i$, istenilen kalkınma düzeyine ulaşılamadığı ve sorunların daha da karmaşık hale geldiği söylenebilir. Dolayısıyla krrsalı yeniden düşünme olgusu altında birçok konu kırsal alanlarda ele alınmaya başlanmıştır. Bu noktada, literatürde yaklaşık son 10 yıldır iome kazanan kursal yaşam kalitesi çalı̧maları, güncel küresel gelişmelerle birlikte krrsal alanların sorunlarm farkl bir çerçeveden ele alarak krrsal sorunlara çözüm olma niteliğine sahip yeni bir kavram olarak görülmektedir. Yaşam kalitesi çalı̧̧malarının; kursalda yoksun olan özelliklerin irdelenmesi, eksikliklerin tespiti ve sorunların çözümüne doğrudan katkı sağlayacak hedef kalkınmaya yönelik sonuçları vermesi gibi güçlü yönleri, konunun bu alandaki önemini artırmaktadır. Bu çalışmada; uluslararası ve ulusal yazında kırsal yaşam kalitesi çalı̧̧malarının kronolojik olarak gelişimi incelenerek yaşam kalitesi çalı̧malarıyla kırsal alanın kalkınmasına etkileri incelenmektedir. Böylece, kursal yaşam kalitesi kavramının kırsal kalkınma ile ilişkisi irdelenerek bir değerlendirme yapılmaktadır.

Anahtar Kelimeler: Yaşam kalitesi, kırsal kalkınma, kırsal alan.

\footnotetext{
${ }^{1}$ Yüksek Lisans Öğrencisi, Gazi Üniversitesi, E-mail: haticekubratemiz@gmail.com

2 Doç. Dr., Gazi Üniversitesi, E-mail: yenigul@gazi.edu.tr

idealkent (c) Kent Araştırmaları Dergisi (Journal of Urban Studies) 


\title{
An Evaluation on the Relationship of Quality of Life Studies with Rural Development
}

\author{
Hatice Kübra Temiz ${ }^{3}$ \\ ORCID: 0000-0002-6307-6534
}

\author{
Sevinç Bahar Yenigül 4 \\ ORCID: 0000-0002-4310-5369
}

\begin{abstract}
The increasing problems in the context of urban and rural, it has been tried to create solutions with lesson development efforts in favor of the countryside. However, it can be said that these efforts have not yielded sufficient results in today's conditions, the level has not been reached to the desired level and the problems have become more complex. For this reason, under the phenomenon of thinking about the countryside, this statement has started to be announced. This decline is seen as a new concept that will gain momentum in the world literature for the last 10 years, and with the current global rise, it is a new concept that has the quality of life addressing the problems from a different framework. Quality of life studies; strengths such as examining the characteristics lacking in rural areas, determining the deficiencies and giving results towards target development that will directly contribute to the solution of the problems increase the importance of the issue in this field. In this study, the development of quality of rural life studies is examined chronologically, and the effects on the development of rural areas with quality of life studies are examined. Thus, an evaluation is presented by examining the relationship between the concept of quality of rural life and rural development.
\end{abstract}

Keywords: Quality of life, rural development, rural area.

\footnotetext{
${ }^{3}$ Postgraduate. Student, Gazi University, E-mail: haticekubratemiz@gmail.com

${ }^{4}$ Assoc. Prof. Dr., Gazi University E-mail: yenigul@gazi.edu.tr 


\section{Giriş}

Küresel boyutta yaşanan güncel gelişmeler, yerleşim alanlarının risklere karşı hangi önlemlerle, hangi sorunlara karşı çözüm üretilmesi gerektiğini göstermektedir. Bu durumun sonucu olarak, her bir yerleşim alanının belli bir düzeyde kendine yetebilme özelliğine sahip olmasının önemi artmaktadır. Bu durum, yerleşim alanlarında; olası durumlar için geliştirilecek senaryolara ihtiyacın olduğunu, aynı zamanda acil durumlarda, müdahaleye en az seviyede ihtiyaç duyacak dirençliliğe sahip olması gerektiğini de göstermektedir. Özellikle yerleşimlerin; yaşamı idame ettirecek temel gereksinimlerini kendi içinde karşllyyor olabilmesi bu kapsamda önem kazanmaktadır. Bu noktada en önemli kıstas; yeteri düzeyde ihtiyaçları karşılamak için gerekli ortamın oluşturulmasıdır. Bu ortamın yaşam koşulları çerçevesinde sağlanmasındaki gerekliliğin karşılığı ise "yaşam kalitesi" kavramı ile açıklanmaktadır.

Yaşam kalitesi kavramının sanayi devrimi ve ikinci dünya savaşının ve sonrasında devam eden kentleşme sorunlarıyla birlikte tartı̧ılmaya başlandığı görülmektedir. Zamanla kavramın sürdürülebilirlik çalışmaları ile desteklenerek, mekânsal boyutta da kentlerin yaşam koşullarının iyileştirilmesi yönünde tartışıldığı görülmektedir. Kalkınma politikaları kapsamında ise yaşam kalitesinin arttırılmasının kalkınmaya katkısı göz önünde bulundurularak kalkınma çalışmalarında da yer bulmaya başladığ görülmektedir. Yaşam kalitesi farklı çalışma alanları ve disiplinlerde de kent planlama alanında da sosyal ve ekonomik boyutlarının yanı sıra mekânsal boyutları kapsamında da ele alınarak tartışılmaya başlanmıştır.

Yerleşim alanlarının kentsel ve kırsal alan olarak tanımlandığı noktada; kırsal alanların yaşam koşullarının kentsel alana göre dezavantajlı olduğu bilinmektedir. Kırsal alanların, düşük nüfus yoğunluğu, fiziksel koşullarındaki engeller, hizmetlere erişim kısıtlılıkları acil durumlara cevap verebilme yetilerinin kentsel alanlara göre daha yetersiz kalmasına neden olmaktadır. Kirsal alanların dezavantajlı durumunu giderecek kalkınma politikaları, günümüzde oldukça yaygın olmakla birlikte, bu politikaların kırsal alanların kalkınmasının önündeki sorunların giderilmesinde yetersiz kaldığı da görülmektedir.

Bu noktada, kırsal alana yönelik politikaların kavramsal yönden ele alınışında bir değişimin gerekliliği ve bu değişimle kırsal kalkınmanın sonuçlarının daha başarılı olacağı ön görülmektedir. Kırsal kalkınma hedeflerini kapsayan ve aynı zamanda kalkınmanın bileşeni olarak kırsal kalkınma 
ile çok yönlü bir etkileşime sahip olan "kırsal yaşam kalitesi" bu noktada kırsal alanların kalkınmasında engel sorunların aşılması yönünde olumlu gelişmeler olarak görülmektedir. Kırsal yaşam kalitesini arttırmaya yönelik sosyal, ekonomik, mekânsal ve memnuniyete dayalı faaliyetlerin gerçekleştirilmesiyle, yerleşim birimlerinin en küçük birimindeki kalite artışının tabandan tavana çok yönlü kalkınma modeliyle sağlanması beklenmektedir. Dolayısıyla kırsalda yaşam kalitesinin arttırılması için öncelikle yaşam kalitesinin hâlihazırdaki durumunun ölçülmesi gerekmektedir.

Yaşam kalitesi ölçüm çalışmaları mekânsal olarak incelendiğinde; kentsel yaşam kalitesi boyutunda geliştiği görülmektedir. Bu ölçüm çalışmaları nitel ve nicel olarak iki başlık altında incelenmektedir. Çalışmalar yaygın olmasına rağmen, ölçüm kriterleri ve göstergelerinin ortak bir başlık altında oluşturulamadığı görülmektedir. Fakat yoğunlaşılan konuların çoğunlukla birbiriyle kesiştiği görülmektedir. Bununla beraber, kırsal yaşam kalitesi ölçüm çalışmaları kentsel çalışmalara göre az ve literatürde ayrıntılı çalışılmayan, genelde nitel başlıklar altında incelenen bir alan olarak görülmektedir. Kırsal yaşam kalitesinin son 10 yılda çalışılma oranında artma görüldüğü ve bu artışın güncel kırsal sorunlarının çözümünde kırsal yaşam kalitesinin önemine de işaret ettiği görülmektedir.

Tüm gelişmeler ve kırsal alana yönelik yapılan çalışmalar; kırsalda değişimin ve bu değişime neden olan dinamiklerin artacağı ve yeni yaklaşımların gelişeceğinin de ön görüsü olarak kabul edilebilir. Söz konusu gelişmeler çok yönlü olup; bu gelişmeler kırsal da kırsal nüfusu barındırabilecek ve kırsal nüfusu yerleşimde tutmayı başarabilecek yenilikçi yaklaşımları gerektirmektedir. Bu noktada kırsal alanların yaşam koşullarının yeteri düzeyde karşılanacağı eylemlerin gerçekleştirilmesi gerekmektedir. Tüm eylemlerin başında; kırsal alanlarla ilgili yaşam kalitesinin hangi düzeyde olduğuna dair bir durum analizinin yapılması gerekmektedir. Yapılması gereken kalkınma politikalarının işlevsel olması ve çözüme yönelik süreçlerin hızlı ilerlemesi açısından doğru stratejilerin belirlenmesinde gerekli zemini hazırlayabilmesinde durum analizinin önemi büyüktür. Böylece kırsaldaki yaşam kalitesini arttırmaya yönelik her eylemin çözüm sürecinde karşılığının ve kalkınmaya etkisinin sonuçları öngörülecektir.

Bu çalışma ile kırsal yaşam kalitesi çalışmalarının; kırsal kalkınmaya katkılarını, bu çalışmaların içeriğiyle kalkınmanın hangi hedef ve boyutlarının sağlandığı, süregelen kırsal kalkınma çabalarında istenilen kalkınmaya ulaşılamamasındaki eksikliklerin giderilmesinde yaşam kalitesinin rolünün belirlenmesi, bu doğrultuda kırsal yaşam kalitesinin belirlenmesi için gerekli 
göstergelerin hangi doğrultuda gelişmesi gerektiği ortaya konulmuştur. Böylelikle kırsal yaşam kalitesi kavramının ulusal ve uluslararası literatürdeki konumu irdelenerek, kavramsal gelişimine katkı sağlanmak istenmektedir.

Çalı̧̧ma kapsamında yaşam kalitesini mekânsal olarak incelemeye öncülük eden kentsel yaşam kalitesi çalışmaları, uluslararası kurum ve kuruluşların yaşam kalitesi ölçümüne dair belgeleri ve literatürde yer alan kırsal yaşam kalitesi çalışmaları incelenmiştir. Bu bağlamda ağırlıklı olarak ele alınan göstergeler kategorize edilerek kırsal kalkınma bağlamında değerlendirilmeler yapılmıştır.

\section{Yöntem}

Çalışmada yöntem olarak ilişkisel araştırma modeli esas alınmıştır. Kırsal kalkınma ile yaşam kalitesi arasında ilişkisel bir bağlam kurulması hedeflenmiştir. Çalışmada ulusal ve uluslararası yazından; üniversitelerin elektronik kütüphanelerinden, internet arama motorlarından, tez tarama motorlarından, bu konuda yayımlanan rapor, bilimsel makale ve bildirilerden yararlanılmıştır.

Bu doğrultuda çeşitli ulusal ve uluslararası arama web sayfasını tarama bölümüne "kırsal yaşam kalitesi" ve "kırsal kalkınma" anahtar sözcüğü yazılarak çıkan sonuçlar üzerinden yazın taraması yapılmıştır. Yapılan tarama esnasında ilgili anahtar kelimelerle yola çkılarak "Şehir ve Bölge Planlama ve yakın disiplinler" çerçevesinde kronolojik olarak ele alınarak araştırmaya sınırlılık getirilmiştir.

\section{Yaşam Kalitesinin Boyutları ve Araştırma Alanı}

Yaşam kalitesi kavramı incelendiğinde öncelikle sağlık alanında ilk araştırmalarını yaptığı ve bunda da sanayi devriminin ve ikinci dünya savaşının etkilerinin bir sonucu ve aynı zamanda artan kentleşme sorunlarının kentte yaşayanların sağlık koşullarının iyileştirilmesi amacıyla yapıldığı görülmektedir. Yaşam kalitesi çalışmalarının araştırma alanları detaylı incelendiğinde bu çalışmaların; bireyin kişisel iyi olma hali ile ilgili araştırmalar, sağlik ile ilgili araştırmalar ve kentsel-çevresel araştırmalar çerçevesinde ele alındığı görülmektedir (Kalkınma Bakanlığı, 2018). Yaşam kalitesi çalışmalarının çerçevesi dışında farklı çalışma alanlarında da ele alındığı görülmektedir (bkz. Tablo1). 
Tablo1. Yaşam kalitesinin araştırma alanları (Kalkınma Bakanlığı, 2018)

\begin{tabular}{llll}
\hline & $\begin{array}{l}\text { Bireyin Kişisel İyi } \\
\text { Olma Hali ile İlgili }\end{array}$ & $\begin{array}{l}\text { Sağlı ile İlgili } \\
\text { Araştırmalar }\end{array}$ & $\begin{array}{l}\text { Kentsel-Çevresel } \\
\text { Araştırmalar }\end{array}$ \\
\hline İlgili Disiplin & Psikoloji, Sosyoloji & $\begin{array}{l}\text { Tip, Psikoloji, Halk } \\
\text { Sağlığı }\end{array}$ & $\begin{array}{l}\text { Ekonomi Coğrafya, } \\
\text { Mimarlık, Şehir ve } \\
\end{array}$ \\
& & & $\begin{array}{l}\text { Bölge Planlama, } \\
\text { Tasarım Kamu } \\
\text { Yönetimi Siyaset } \\
\end{array}$ \\
& & & Bilimi \\
\hline Çalışma Alanları & Bireyin İyi Olma & $\begin{array}{l}\text { Tüm Koşulların } \\
\text { Durumu Mutluluk }\end{array}$ & $\begin{array}{l}\text { İnsan-Çevre İlişkileri } \\
\text { Sağloğıluma Etkileri }\end{array}$ \\
& & ve Etkileşimleri \\
& & & \\
\hline
\end{tabular}

Tablo 1. incelendiğinde; çalışma alanları ve ilgili disiplinlerin yaptıkları çalışmalarda sağlık, kentsel ve çevresel ana araştırma alanlarının birbiriyle bağımsız düşünülmeyerek etkileşim halinde olduğu ve bu durumun özellikle son güncel gelişmelerle birlikte yoğunluk kazandığı da görülmektedir.

Konunun insan hakları boyutu da öne çıarken; insan hakları konusunda yaşanan gelişmeler sonrasında yaşam kalitesi kavramı yaygınlaşarak yaşam kalitesinin arttırılması yalnızca bir hak olarak soyut anlamda kalmayıp, farklı boyutlarda da uygulanmaya başlandığı görülmektedir (Tekeli, Güleri Vazioğlu, Algan ve Dündar, 2003). Yaşam kalitesinin boyutları ve bileşenleri bir araya getirildiğinde ortak bir çerçevede; hizmetler: sağlık, fiziksel çevre, toplumsal gelişim, kişisel gelişim ve güvenlik gibi başlıklar ön plana çımaktadir.

Üçer, (2009)'e göre yaşam kalitesi konusunun ele alındığı boyutlar uluslararası yazın kapsamında incelendiğinde, araştırma sayısı ve yoğunlaşılan boyutların öncelikle sağlık ve daha sonra mekân boyutunda olduğu görülmektedir. Sağlık boyutu Dünya Sağlık Örgütü'nce; fiziki, ruhsal ve sosyal anlamda tam iyi olma hali olarak tanımlanmakta; bu durumda yaşamın ve yaşam kalitesinin tamamını kapsar hale gelmektedir. Mekân boyutu ise ilk olarak Perloff, (1969) tarafindan ele alınarak kentsel alanda yaşayanların yaşam kalitesinin doğal ve yapılı çevrenin karşılıklı etkileşmesiyle belirlendiği üzerinde durulmuştur. Bu çalışmayla birlikte yaşam kalitesinin mekânsal olarak irdelenmesi özellikle 1980li yıllardan sonra ivme kazanarak birçok çalışmada ele alınmıştır.

Yaşam kalitesinin mekân boyutu çalışılırken Türksever, (2001)' in ifade ettiği üzere araştırmalarda genel olarak, istatistiksel analiz yöntemleri kullanılarak; yaşamdan hoşnutluğu etkileyen etkenler belirlenmeye, kentsel yerleşimler arası karşılaştırmalar yapılmaya, kentsel yaşamı kötü hale getiren 
etmenler ortaya konulmaya ve değişen yaşam koşullarına göre bireylerin kentsel yaşamdaki tercihlerinin ortaya konulması öne çıkmıştır.

Yerleşim alanları sınıflandırmasına göre kentsel ve kırsal alan sınıflandırması yapıldığında mekân boyutundaki yaşam kalitesi çalışmalarının özellikle kentsel alanlarda başlayarak bu alanlarda çalışmaların yoğunlaştığı görülmektedir.

\section{Kırsal Yaşam Kalitesi Kavramının Ortaya Çıkışı}

Kırsal yaşam kalitesi kavramı kentsel yaşam kalitesi kavramına göre daha yeni olup, literatürde son on yıldır tartışılmaya başlanmıştır. Kavram ve dolayısıyla kırsal alanlarda yaşam kalitesi çalışmaları 2000'li yılların başında görülmeye başlanmıştır. Yaşam kalitesi kavramının kırsal alanlarda irdelenmeye başlanmasında kentleşmenin etkisiyle artan kır-kent sorunlarına çözüm arayışı etkili olmuştur. Ulusal ve uluslararası literatür incelendiğinde, kırsal yaşam kalitesi bağlamında yapılan çalışmaların 2000 yılı itibariyle yapıldığı, çalışmaların daha çok Avrupa ülkelerinde yoğunlaştı̆̆ 1 ve farklı çalışma disiplinlerince yapıldığı görülmektedir (bkz. Tablo 2).

Tablo 2. Kırsal yaşam kalitesi çalışmalarının ayrıntılı incelenmesi (Yazarlar tarafından üretilmiştir)

\begin{tabular}{llll}
\hline Araştırmacılar & $\begin{array}{l}\text { Çalışma } \\
\text { Alanı }\end{array}$ & $\begin{array}{l}\text { Araştırma } \\
\text { Yılı }\end{array}$ & $\begin{array}{l}\text { Araştırmacıların } \\
\text { Bölümleri }\end{array}$ \\
\hline $\begin{array}{l}\text { Deller, Tsai, Marcouillerve } \\
\text { English }\end{array}$ & Amerika & 2001 & $\begin{array}{l}\text { Şehir ve Bölge } \\
\text { Planlama, Tarım } \\
\text { Ekonomisi, Ormancllı }\end{array}$ \\
\hline $\begin{array}{l}\text { Luiz, D'Agostini Æ Alfredo } \\
\text { C. Fantini }\end{array}$ & - & 2008 & Tarım ve Çevre \\
\hline James & Amerika & 2011 & $\begin{array}{l}\text { Coğrafya, Bölgesel } \\
\text { Kalkınma }\end{array}$ \\
\hline Rezvani ve Mansourian & İran & 2011 & $\begin{array}{l}\text { Şehir planlama, } \\
\text { Coğrafya, Kırsal }\end{array}$ \\
& & & Planlama \\
\hline Brereton, Bullock, Clinch ve & İrlanda & 2011 & $\begin{array}{l}\text { Coğrafya, Mimarlık, } \\
\text { Scott }\end{array}$ \\
& & & Şehir Planlama ve \\
& & & Çevre \\
\hline Hovardaoğlu & Sürkiye & 2012 & $\begin{array}{l}\text { Slanlama } \\
\end{array}$ \\
\hline Zhou & & Bölge Planlama, \\
& Çin & 2014 & Coğrafya \\
\hline
\end{tabular}




\begin{tabular}{|c|c|c|c|}
\hline $\begin{array}{l}\text { Khorasani,Hajiloo ve } \\
\text { Valizade }\end{array}$ & İran & 2015 & $\begin{array}{l}\text { Coğrafya ve Kirsal } \\
\text { Planlama }\end{array}$ \\
\hline Zarnekow ve Henning & Almanya & 2016 & $\begin{array}{l}\text { Tarım ekonomisi, } \\
\text { Kırsal Planlama }\end{array}$ \\
\hline Vaznonienè ve Kiaušienė & Litvanya & 2017 & $\begin{array}{l}\text { Sosyal Bilimler, Ziraat } \\
\text { ve Tarım }\end{array}$ \\
\hline Brambert ve Kiniorska & Polonya & 2018 & $\begin{array}{l}\text { Coğrafya, Çevre } \\
\text { Bilimleri, Sosyal } \\
\text { Ekonomik Coğrafya }\end{array}$ \\
\hline $\begin{array}{l}\text { Chengli, Yanhua,Guohua, } \\
\text { Shanshan,Luyao }\end{array}$ & Çin & 2018 & $\begin{array}{l}\text { Şehir ve Kırsal } \\
\text { Planlama, Çevre, Veri } \\
\text { Madenciliği }\end{array}$ \\
\hline $\begin{array}{l}\text { Michalska-Żyła ve Marks- } \\
\text { Krzyszkowska }\end{array}$ & Polonya & 2018 & $\begin{array}{l}\text { Kirsal ve Kentsel } \\
\text { Sosyoloji, Mekânsal } \\
\text { Ekonomi ve Yerel } \\
\text { Yönetim }\end{array}$ \\
\hline $\begin{array}{l}\text { Casini,Boncinelli, Contini, } \\
\text { Gerini, ve Scozzafava }\end{array}$ & İtalya & 2018 & $\begin{array}{l}\text { Tarım Ekonomisi, } \\
\text { Çevre, Orman ve Gıda } \\
\text { Bilimleri }\end{array}$ \\
\hline $\begin{array}{l}\text { Moser,Peter, Fengler ve } \\
\text { Strohm-Lömpcke, }\end{array}$ & Almanya & 2018 & $\begin{array}{l}\text { Ekoloji ve Ziraat, Kırsal } \\
\text { Araştırmalar }\end{array}$ \\
\hline Halonen ve Kattilakoski & Finlandiya & 2018 & $\begin{array}{l}\text { Coğrafya ve Tarih, } \\
\text { Sosyal Bilimler }\end{array}$ \\
\hline Fischer ve Born & Avusturya & 2018 & $\begin{array}{l}\text { Mekânsal Planlama ve } \\
\text { Kırsal Kalkınma, } \\
\text { Mekânsal Planlama }\end{array}$ \\
\hline Bernard & Çekya & 2018 & Sosyal Bilimler \\
\hline Blekesaune ve Haugen & Norveç & 2018 & $\begin{array}{l}\text { Sosyoloji ve Siyasal } \\
\text { Bilimler, Kırsal ve } \\
\text { Bölgesel Araştırmalar }\end{array}$ \\
\hline $\begin{array}{l}\text { Petrová-Kafková, } \\
\text { Vidovićová ve Wija }\end{array}$ & Çekya & 2018 & $\begin{array}{l}\text { Sosyal Bilimler, Siyasal } \\
\text { Bilimler }\end{array}$ \\
\hline $\begin{array}{l}\text { Antonã-N, Vaishar \& } \\
\text { Vidovićová, Lucie \& } \\
\text { Figueiredo, Elisabete }\end{array}$ & $\begin{array}{l}\text { Avrupa } \\
\text { Birliği }\end{array}$ & 2018 & $\begin{array}{l}\text { Ziraat ve Peyzaj } \\
\text { Mimarlığı Bölümü, } \\
\text { Sosyal ve Siyasal ve } \\
\text { Bölgesel Bilimler }\end{array}$ \\
\hline Küçükoğul ve Türkoğlu & Türkiye & 2021 & $\begin{array}{l}\text { Şehir ve Bölge } \\
\text { Planlama }\end{array}$ \\
\hline
\end{tabular}


Tablo 2 incelendiğinde; ilk kırsal yaşam kalitesi ölçüm çalışmasının Amerika özelinde gerçekleştiği ve ilgili çalışmanın "Şehir ve Bölge Planlama" alanında yapıldığı görülmektedir. Kırsal yaşam kalitesi konusunda Tablo 2 'de ele alınan 22 çalışmanın 8'inin "Şehir ve Bölge Planlama" disiplinince ele alınması bu anlamda yetkin bir disiplin olduğunu göstermektedir. Daha sonrasında Avrupa özelinde çalışmaların yoğunlaştı̆̆ı ve bu çalışmaların Avrupa Birliği "Avrupa Kırsal Kalkınma Programının Kalkınma Hedefi" altında çalışmalar gerçekleştirdiği görülmektedir. Dolayısıyla kırsal alanın kalkınması amacıyla gerçekleşen bir programda yaşam kalitesinin bu denli çalışılması dikkat çeken ve kalkınma ve kırsal yaşam kalitesi arasındaki ilişki için önemli bir gelişme olarak görülmektedir.

Tablo 2'de yer alan tüm kırsal yaşam kalitesi çalışmalarının kırsal kalkınmayla olan ilişkileri incelendiğinde; tüm çalışmalarda yoğunlukla fiziksel altyapı, sosyal altyapı, ekonomi, kamu hizmetleri ve erişim gibi alt başlıkların incelendiği görülmüştür. Bunun dışında; Vaznonienė ve Kiaušienė (2017) sosyal altyapı, Deller (2001) ise kırsal ekonomi yönüne ağırlık vererek kırsal kalkınmanın bu yönlerine katkı sağlamayı amaçlamışlardır. Ortak başlıkların dışında kırsal alanların yönetim ve siyaset boyutuna da yer veren çalışmalar da görülmektedir (Zarnekow ve Henning, 2016, Chengli, v.d. , 2018; Deller, 2001; Michalska-Żyła ve Marks-Krzyszkowska, 2018; Moser, 2018). Toplumsal kalkınmanın en önemli boyutlarından biri olan katılım Michalska-Żyła ve Marks-Krzyszkowska, (2018) ve Khorasani,Hajiloo ve Valizade, (2015) tarafından çalışmalarına dahil edilmiştir. Bunun dışında araştırma evrenini sınırlandırarak toplumda dezavantajlı olarak adlandırılan gruplardan yaşlı nüfusun; özellikle kırsalda yaşayan yaşlı nüfusun yaşam kalitesinin arttırılmasına yönelik çalışmalar da yer almaktadır (Blekesaune ve Haugen, 2018; Petrová-Kafková, Vidovićová ve Wija, 2018).

Bu çalışma kapsamında Tablo 2'de yer alan çalışmalara referansla, çalışmaların kırsal yaşam kalitesi ve kalkınmaya ilişkin teorik tartışmalarından ve bulgularından yapılan çıarım sonucu; kırsal alandaki yaşam kalitesini arttırmak için kırsal kalkınma çabasının doğrudan bu sürece dâhil olması gerektiği görülmektedir. Kalkınma sürecine dâhil edilen araçların aynı zamanda yaşam kalitesi kriterlerinde de kullanıldığı ortaya çıkmaktadır. Çalışmaların belli kriterlerle yaşam kalitesini ele aldığı ve bu başlıkların kalkınmayı gerektiren konu başlıkları olduğu görülmektedir. Ayrıca çalışmaların gerçekleştiği disiplinlerin ve çalışmayı gerçekleştiren araştırmacıların 
kırsal kalkınma konusunda yeterli donanıma da sahip olduğu görülmektedir.

Türkiye'de kırsal yaşam kalitesine ilişkin ulusal yazında Hovardaoğlu, (2012)'nun çalışması yer almaktadır. Hovardaoğlu'nun yaptığı çalışma incelendiğinde, kırsal yaşam kalitesi kavramsal olarak ele alınmış ve kırsal kalkınma politikaları bağlamında değerlendirilmiştir. Bir diğer çalışma ise Küçükoğul ve Türkoğlu, (2021) tarafından yapılmıştır. Çalışmada doğrudan uygulamaya yönelik bir örnek olarak kırsal mekânda kırsal yaşam kalitesinin ölçümü için yöntem geliştirilmiştir. Çalışma içerik açısından kırsal kalkınmayla doğrudan örtüşen parametreleri kullanırken kırsal yaşam kalitesinin arttırılmasına yönelik öneriler geliştirmiştir.

\section{Yaşam Kalitesi ve Kırsal Yaşam Kalitesi Kavramının Türkiye'de Politika Belgelerindeki Yeri}

Yaşam kalitesi kavramı Türkiye'de ulusal yazında bilimsel çalışmalarda 2000li yıllarla birlikte yer almıştır. Türkiye'de, kurumsal düzeyde yapılan yaşam kalitesi çalışmaları iki grupta ele alınmaktadır. Bunlar; yaşam kalitesinin ölçülmesine ve yaşam kalitesi göstergelerinin belirlenmesine dair çalışmalardır. Yaşam kalitesinin belirlenmesine yönelik uygulamaları içeren alan çalışmaları, Devlet Planlama Teşkilatı (DPT) ve Devlet İstatistik Enstitüsü (DİE) tarafından geçekleştirilmiştir. Yaşam kalitesi göstergelerinin belirlenmesini içeren teorik çalışmalar ise, Habitat II Türkiye Ulusal Komitesi (TUK), Türkiye Bilimler Akademisi (TÜBA) ve Bayındırlık ve İskân Bakanlığı (BİB) tarafından ortaya konulmuştur. Yakın geçmişte ise Türkiye İstatistik Kurumu (TÜIK), Kalkınma Bakanlığı'nca hazırlanan Kalkınma Planları ve ilgili ihtisas raporları, bazı özel dergi ve kuruluşlar, Ekonomi Kalkınma ve İşbirliği Örgütü (OECD), Türkiye Ekonomi ve Politika Araştırmaları Vakfı (TEPAV), Uluslararası Rekabet Araştırmaları Kurumu (URAK), Ekonomi ve Dış Politika Araştırma Derneği (EDAM) gibi çalışmalarda gerçekleştirilmiştir (Üçer, 2009, s.46).

Kalkınma alanında önemli belgeler olan Beş Yıllık Kalkınma Planları incelendiğinde; kalkınma planlarında yaşam kalitesi kavramının VII. ve VIII. Beş Yıllık Kalkınma Planına kadar yer almadığı söylenebilir. Ancak kırsal alanda kalkınmaya yönelik ve dolayısıyla yaşam kalitesine ilişkin dolaylı hedeflerin Cumhuriyet Dönemine kadar uzandığı da yapılan çalışmalarda görülmektedir. Bu hedeflerin kırsaldaki yaşam kalitesini arttırmaya yönelik olduğu görülmektedir. Bu dönemde hedefler, 442 Sayılı Köy Kanunu, ardın- 
dan tarımsal destekleme politikası gibi kırsal alanın yaşam kalitesini arttırmaya ve kalkınmasına yönelik uygulamalar ile desteklenmiştir. Planlı döneme geçiş ile birlikte kalkınma planlarında kırsal alanlara yönelik farklı yaklaşımlar geliştirilmiştir. Kalkınma planlarındaki kırsala yönelik stratejiler incelendiğinde:

I. Beş Yıllık Kalkınma Planında; toplum kalkınması modelinin uygulanması, kredilendirme, pazarlama, kooperatifleşme ve toprak reformu yapılması, II. Beş Yıllık Kalkınma planında; toplum kalkınması modeline devam edilmesi, kırda yaşayanların kalkındırılması, tarıma ucuz girdiler sağlanması, kooperatifleşme, toplum kalkınması enstitüsünün kurulması, köykent ve tarımkent modellerinin geliştirilmesi, III. Beş Yıllık Kalkınma Planında; köylünün yaşam düzeyinin yükseltilmesi, tarım ve toprak reformu yapılması, üretimin arttırılması, kooperatifleşme, kredilendirme ve pazarlama olanaklarının geliştirilmesi, merkez köy modelinin geliştirilmesi, IV. Beş Yıllık Kalkınma Planında; toprak reformunun yapılması, kooperatifleşme, kırsal kesimde kalkınma için devlet desteğinin sağlanması, Kalkınmada Öncelikli Yöreler (KÖY) kavramı getirilerek bu alanların geliştirilmesi, V. Beş Yıllık Kalkınma planında; entegre kırsal kalkınma projeleri uygulanması, tarım topraklarının mülkiyetten kaynaklanan sorunlarının çözümü, VI. Beş Yıllık Kalkınma Planında; kırsal alan planları yapılması, kırsal alanda tarım dışı faaliyetlerin desteklenmesi, toprak düzenlemesi, eğitim projeleri yapılması gibi stratejiler oluşturulmuştur. Böylelikle tüm bu stratejilere bakıldığında; kavramin belgelerde yer almasa da dolaylı olarak gündemde yerini koruduğu görülmektedir (Çelik, 2006).

Türkiye'de yaşam kalitesini önemli bir araştırma konusu olarak ele alan en önemli belge 2018 yılında yapılan Kalkınma Bakanlığı tarafından hazırlanan 11. Kalkınma Planında yer alan Kentsel Yaşam Kalitesi Özel İhtisas Raporu'dur. Raporda, yaşam kalitesi şehir ve bölge planlama disiplini çalışmaları kapsamında ele alınarak mekâna yönelik değerlendirmeler yapılarak kalkınmanın çok boyutlu olarak ele alındığı görülmektedir.

Kentsel yaşam kalitesinin ayrıntılı şekilde kalkınma planında ele alınmasıyla, kalkınma planları özelinde kırsal yaşam kalitesi konusunun bu belgelerde nasıl gelişme gösterdiği incelenmiş ve bu inceleme Şekil 1 ile aktarılmaya çalışılmıştır. 


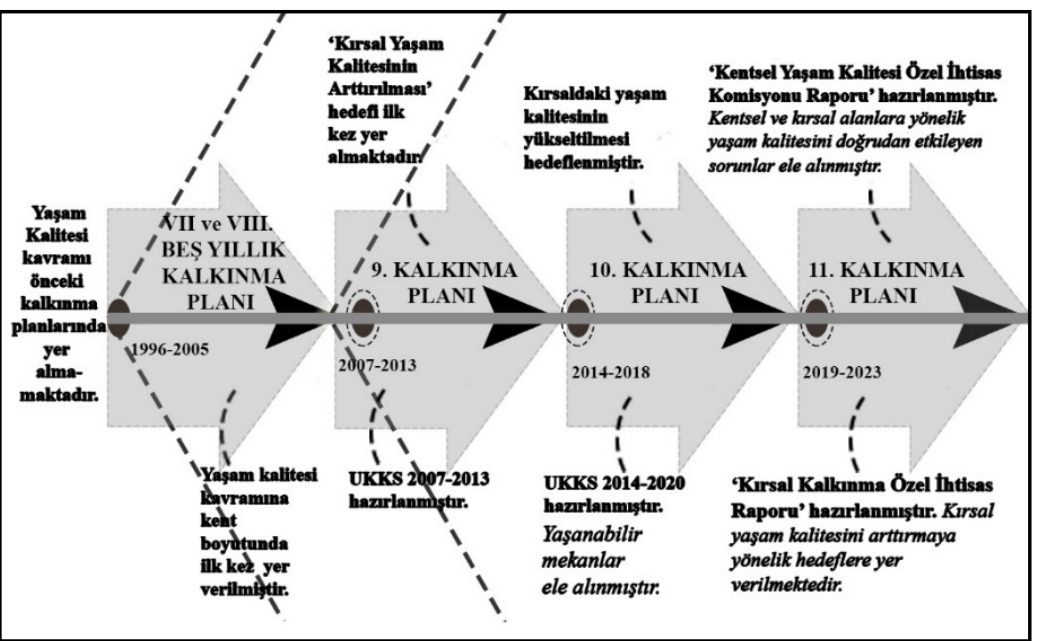

Şekil 1. Yaşam Kalitesi Kavramının Kalkınma Planları Dâhilinde Gelişim Kronolojisi (Yazarlar tarafından üretilmiştir)

Şekil 1'den de anlaşılacağı üzere, VII. ve VIII. Beş Yıllık Kalkınma planı öncesinde kavramsal olarak yaşam kalitesine yer verilmediği söylenebilir. VII. ve VIII. Beş Yıllık Kalkınma Planıyla birlikte yaşam kalitesi kavramının kentsel alan boyutunda yer aldığı görülmektedir. Bu noktada 9. Kalkınma Planının kırsal yaşam kalitesinin arttırılması yönünde hedef belirleyerek bu konuda ilk kavramsal yönde ele alışı ortaya koyduğu söylenebilir. 10. ve 11. Kalkınma Planlarında da kırsal yaşam kalitesine dair hedeflerin arttığı, 11. Kalkınma Planında hazırlanan kentsel yaşam kalitesi özel ihtisas komisyonu raporunda kentsel ve kırsal alana yönelik sorunlara da yer verilerek bu konuda daha ayrıntılı çalışmalara yer verildiği görülmektedir. Ayrıca 11. Kalkınma planı dâhilinde hazırlanan "Kırsal Kalkınma Özel İhtisas Raporu'nda" yaşam kalitesinin arttırılmasına yönelik hedef politikalara yer verilmesi, kırsal kalkınma ile kırsal yaşam kalitesi arasındaki güçlü ilişkinin kavranmaya başlanıldığının ve bu noktada adımların atıldığı göstergesi olarak kabul edilebilir. Ancak bu belgeler incelendiğinde kentsel yaşam kalitesinin ele alınma oranının kırsal yaşam kalitesine göre çok daha fazla olduğu, yaşam kalitesi çalışmalarının kırsalda henüz beklenilen gelişmeyi gösteremediği söylenebilir. Bu süreçte kırsal yaşam kalitesini konu alan her bir çalışmanın bu anlamda örnek teşkil edeceği aşikârdır.

\section{Yaşam Kalitesinin Kırsal Kalkınmadaki Rolü}

Kırsal alanda istenilen kalkınma düzeyine ulaşabilme hedefinin gerçekleşip gerçekleşmediğinin çözümlemesinde, bugüne kadar yapılmış kırsal kalkınma çalışmalarının hedef ve sonuçlarının irdelenmesi gerekmektedir. 
İlgili yazın incelendiğinde; yapılan çalışmaların ortak paydasında kırı yeniden düşünmek, kırsala yeni senaryolar yüklemek ve güncel çözüm arayışlarıyla gidilmesi gerekliliği vurgusunun yapıldığı görülmektedir. Bu noktada kırsal kalkınmanın "kırsal kesimdeki asgari yaşam kalitesinin ülke ortalamasına yaklaştırılması hedefiyle kırsal toplumun iş ve yaşam koşullarının kentsel alanlarla uyumlu olarak kendi yöresinde geliştirilmesi ve sürdürülebilir kılınması" amacının tanımlanmasıyla yaşam kalitesi kavramının bu amaç doğrultusunda oldukça ön plana çıktı̆̆ görülmektedir (T.C Gıda Tarım ve Hayvancilık Bakanlığı, 2015).

Kalkınma; değişme, gelişme, büyüme ve ilerleme süreçlerini içeren bununla beraber sosyal, ekonomik, mekânsal ve kültürel boyutlarıyla da ele alınan bir kavram olarak ortaya çıkmaktadır. Kalkınmanın özellikle ekonomik boyutuyla ele alındığı ve tek bir itici güçle gerçekleştirilmeye çalışılan çalışmalar kapsamında yapıldığı ve bunların da başarısız sonuçlarla sonuçlandığı görülmektedir. Bu durum kalkınmanın ekonomik kalkınma ile tek başına ilişkilendirilmesinin yetersiz kaldığı, içeriğinde değişime ihtiyaç duyulduğu tartışmaların da başlatmıştır. Bu tartısmalar 20. yy'ın sonlarında hız kazanırken, kalkınma kavramının sosyal-refah içeriğiyle ele alınması; nitelikli doğal, sosyal, ekonomik, fiziksel ve kültürel çevrenin varlığı anlamlarını kapsayan yaşam kalitesi yönü ile ölçülmesinin daha başarılı sonuçlar doğuracağına ilişkin görüşleri de oluşturmuştur (Başkaya,2000, s.19).

Kalkınma kavramının evrilmesi sonucunda odak olan ekonomik kalkınmanın yerini insani kalkınma anlayışı almaya başlamıştır. İnsani kalkınmanın ölçülmesi için oluşturulan endeksler incelendiğinde; sağlık, eğitim ve yaşam kalitesi gibi 3 temel boyutun ölçüm için referans alındığı görülmektedir. Yaşam kalitesinin öneminin kalkınmanın üzerindeki ve ölçümündeki payının önemi de böylece ortaya konulmuştur (UNDP, 2020: 19).

Çelik (2006)'e göre kırsal kalkınma; "kırsal alanda yaşayanların yaşam kalitelerinin arttırılması, gelirlerinin artması ve gelir dağılımının adaletli olması, sağlık ve eğitim vb. hizmetlerinin sağlanması, doğal kaynakların koruma-kullanıma dengesinin sağlanması ve bireylerin kalkınmaya katılımlarının desteklenmesi ve sağlanması" olarak tanımlanmıştır. Tanımda da özellikle en başta yer alan yaşam kalitesi ifadesi kırsalın kalkınmasında yaşam kalitesi boyutunun önemine vurgu yapmaktadır. Kırsaldaki kalkınmanın doğrudan yaşam kalitesi ile paralellik göstereceği, yaşam kalitesindeki artışla kalkınmaya doğrudan veya dolaylı bir ivmenin kazandırılacağı görüşü oluşmaktadır. 
Kırsal alanlarda tespit edilen tüm eksiklikler birbirini tetikleyerek kalkınmanın önünde engel olarak görülerek döngüsel bir hal almaktadır. Bu noktada FAO/RAPA (1988)'nın çalışmasına göre kırsal alanda kalkınma için tayin edilen süreçlerin ilerleyişleri ve hangi başlıklar altında projelendirildiğine bakıldığında; kırsal alan etüdü (envanter toplama), problemlerin tanımlanması (sorun analizi), planlama (projelendirme), izleme, gözden geçirme, uygulama ve değerlendirme gibi süreçler özellikle ön plana çıkmaktadır.

Tüm bu süreçler incelendiğinde; en çok zaman ve çabanın harcandığı sürecin envanter toplama ve problemlerin tanımlanması çalışmaları olduğu araştırmacıların ortak görüşü olarak ortaya çıkmaktadır. Bu iki sürecin başarılı ve sistematik bir şekilde ilerlemesi yaşam kalitesi çalışmalarında da önem arz etmektedir. Yaşam kalitesi ölçüm çalışmaları nesnel ve öznel göstergeler olarak iki grupta yer almaktadır. Nesnel göstergeler ile somut veri, tanımlama ve analizi gerçekleştirmede, öznel göstergeler ise kırsal halkın refah, memnuniyet ve algılarını ilgili gösterge setleriyle ölçerek kırsalda istenilen insani kalkınma hedefleri dâhilinde kırsal kalkınma aşamalarının en önemli iki kısmını gerçekleştirebilmektedir.

Kırsalda istenilen kalkınma düzeyine ulaşabilmede verilerin işlenmesi için öncelikle kırsala ait bilgilerin belirli göstergeler halinde somut bir şekilde bir araya getirilebilmesi gerekmektedir. Bu noktada kırsal göstergelerin önemi artmaktadır. Kırsal göstergeler; kırsal alanların özelliklerini çok boyutta ele alan; kırsaldaki kriterlerin istatistikî biçimde üretildiği gösterge setleridir. Bu noktada kırsal alanda yapılacak her bir yaşam kalitesi çalışması için kırsal gösterge setlerinden yararlanılacaktır. Böylece; ulusal ve uluslararası yazında kırsal gösterge setleri incelendiğinde; uluslararası yazında yer alan göstergelerin nesnel olarak; fiziksel, ekonomik toplumsal ve çevresel göstergelere, öznel olarak ise alg1, refah ve memnuniyet göstergelerine yer verildiği görülmektedir. Türkiye'de ise Kalkınma Bakanlığı ve TÜİK işbirliğiyle oluşturulan kırsal göstergelerin, nesnel olarak; kırsal ekonomi, kırsal çevre, kırsal yerleşim, kırsal toplum, öznel olarak; yerel kalkınma kapasitesi adı altında başlıklar halinde setlerin oluşturulduğu görülmektedir (T.C Gıda Tarım ve Hayvanclık Bakanlığı, 2015). Oluşturulan başlıkların içeriği incelendiğinde, her başlık ile kalkınmanın gerektirdiği tüm konulara değinilme amacı hedeflense de; ilgili alt başlıklar ve dolayısıyla bu başıkların altındaki parametrelerin daha ayrıntılı bir şekilde ortaya koyulması ve mevcut haliyle gelişime açık olduğu görülmektedir. $\mathrm{Bu}$ şekilde ulusal bir belge ile kırsal gösterge setlerinin oluşturulması tüm araştırma- 
larda ortak bir dil olması açısından önemli bir gelişme olarak karşımıza çıkmaktadır. Fakat Uluslararası yazında gösterge setlerinin içerikleri incelendiğinde; Türkiye'deki kırsal gösterge setlerinin nesnel ölçütte eksiklikler barındırdığı, öznel ölçütte ise tam anlamıyla karşılık bulamadığı da görülmektedir. Bu noktada öznel ve nesnel parametreleri bir arada kullanan, yeni bir çalışma olarak ortaya çıkan Küçükoğul ve Türkoğlu(2021)'un çalışması; özellikle ulusal bağlamda literatüre olan katkısıyla oldukça önem kazanmaktadır. Ortaya koydukları çalışma ile kırsal yaşam kalitesini doğrudan gösterge ve setlerle değil de bir üst başıkta yeni bir yaklaşım(Place Standart) ile değerlendirmeye almışlardır. Çalışmaya girdi olan söz konusu yaklaşımın içinde yer alan parametre setlerinin çok yönlülüğü ve aynı zamanda sonuçların kırsal yaşam kalitesinin gerektirdiği bağlamlara önem verdiği görülmektedir.

\section{Sonuç}

Günümüzde kentleşme dinamikleriyle birlikte artan kentsel ve kırsal alanlar arasındaki ikilemler kırsal kalkınma politikalarında yenilikçi yaklaşımlara yönelik çabaların artmasına neden olmaktadır. Bu kapsamda beklenen kalkınma düzeyine ulaşlabilmesinde yeni yaklaşım ve yeni kavram arayışlarına ihtiyaç duyulmuştur. Bu kapsamda, kalkınmanın da tanımında yer bulan yaşam kalitesi kavramının önemi artmıştır. Bu durum kalkınma ve yaşam kalitesi ve dolayısıyla kırsal kalkınma ve kırsal yaşam kalitesi arasında yadsınamayacak bir kavramsal ilişki olduğunu göstermektedir.

Bu ilişkiler yakından incelendiğinde; kalkınma kavramınn ekonomik, sosyal ve mekânsal boyutunun yanı sıra eksik olan yaşam kalitesi yönüyle istenilen insani kalkınma düzeyine ulaşılabileceği görülmektedir. Bu doğrultuda insani kalkınmayı ölçmeye yarayan endeksler incelendiğinde ise yine yaşam kalitesi boyutunun ele alındığının görülmesiyle; yaşam kalitesiyle kalkınma arasındaki güçlü bağı kantlar niteliktedir.

Bin yıl kalkınma hedefleri artan küresel problemler için; dezavantajlı nüfus ve yerleşimlere öncelik veren kalkınma hedeflerini ortaya koymaktadır. Bu noktada kırsal alanlar tüm bu sorunları diğer yerleşim yerlerine nazaran daha çok barındırması nedeniyle kırsal kalkınma hedeflerinin arttırılması gerekmektedir.

Kırsal alanda oluşturulan kalkınma amaçlanı doğrultusunda; yaşam kalitesinin kalkınma ile aynı amaç doğrultusunda ve kalkınma ile yaşam kalitesinin birbirini kapsar nitelikte olduğu görülmektedir.

Yaşam kalitesinin mekân boyutunun sağlık boyutundan sonra en çok çalışılan boyut olmasıyla, uluslararası yazında kentsel ve kırsal yaşam kalitesi çalışmalarının öneminin arttı̆ğ, günümüz kırsal kalkınma yaklaşımlarında ise kırsal 
alanda mekânsal düzenlemelerin yapılması yönündeki yeni yaklaşımların da öne çıktı̆ı görülmektedir.

Kırsal yaşam kalitesi çalışmalarının son yıllarda artş̧ göstermesinin günümüz kentsel ve kırsal alan sorunları dâhilinde çözüm arayışı içerisinde olduğunu kantlar niteliktedir.

Türkiye'de kırsal yaşam kalitesi dünya literatüründe yer alan örnekleri gibi gelişim gösterememekte, Türkiye'de kırsal alanda yaşam kalitesi yalnızca kavramsal olarak kırsal kalkınma strateji belgelerinde hedef olarak yer almaktadır. Bu da kırsal alan ve kırsal kalkınma çalışma alanı içinde gerek akademik çalışmalarda ve gerekse uygulamada gerekli önemin huzla verilmesini gerektiğini göstermektedir.

Uluslararası akademik platformda yapılan kırsal yaşam kalitesi çalışmaları incelendiğinde; ilk çalışmanın ve yapılan çalışmaların sayı olarak azımsanmayacak kadar şehir ve bölge planlama disiplinince ortaya konulduğu, planlama disiplininin bu konuda daha yetkin olunması gereken bir alan olduğunu göstermektedir. Yaşam kalitesi konusunun yer aldığı uluslararası sözleşmelerde Türkiye'nin de taraf olması önemli bir gelişme olarak görülürken, bu gelişmeler dâhilinde kentsel boyutta yaşam kalitesi alanında çalışmalar gelişim göstermekte, benzer gelişmenin kursal boyutta da olması beklenmektedir.

Kırsal alan sorunları ile geliştirilen kırsal kalkınma eyleminin aşamaları ele alındığında; kırsal kalkınma çalışmalarında kırsal alana dair envanter eksikliği bu çalışmaların en önemli kısıtllıklarından biridir. Alandaki bir diğer eksiklik ise kalkınma için oluşturulan politikaların kalkınmayı gerçekleştirememesidir. Bunun en önemli nedeni ise kırsal alandaki sorun tespiti ve tanımının doğru yapılamaması olarak görülmektedir. Yaşam kalitesi ölçüm çalışmalarıyla kırsal alan analizi hem nesnel hem de bu öznel göstergeler ile elde edildiğinden ortaya çıkan sorunlara karşıllk hedef politikaların oluşturulması açısından önem kazanmaktadır.

Kırsal kalkınmanın gerçekleşmesi için oluşturulması gereken kırsal envanterin Türkiye özelinde eksikliği; mevcut kırsal göstergelerde görülmektedir. Bu eksiklikler nesnel ve öznel olarak yer alsa da kırsal kalkınmada yerel kalkınma kapasitesi olarak belirlenen refaha ve memnuniyete dayalı gösterge setinin içeriği oluşturulamamıştr. Dolayısıyla kalkınmanın yaşam kalitesince öznel kısmında büyük eksiklikler söz konusudur. Türkiye'de gerçekleştirilecek kırsal yaşam kalitesi ölçüm çalışmalarıyla en önemli girdinin eksik kırsal göstergelerin belirlenmesi ve oluşturulmasına sağladığ katkısı olması beklenmektedir.

Kırsal kalkınmanın mevcuttaki en büyük eksiğinin "kırsal yaşam kalitesi göstergeleri" halinde verilmesiyle daha profesyonel ve teknik bir ilerleyiş ortaya konularak kalkınmaya olan katkısının gerçekleşmesi beklenmektedir. 


\section{Extended Abstract}

\section{An Evaluation on the Relationship of Quality of Life Studies with Rural Development}

\author{
Hatice Kübra Temiz \\ ORCID: 0000-0002-6307-6534
}

\author{
Sevinç Bahar Yenigül \\ ORCID: 0000-0002-4310-5369
}

Current developments on global scale show which measures should be taken against risks in residential areas and solutions should be produced against the problems. As a result of this situation, the importance of each residential area which has a certain level of self-sufficiency is increasing. This situation, in residential areas; also shows that we need scenarios to develop for possible situations, and that it should also have the resilience to require minimal intervention in emergency situations.

Especially the settlements; in this respect, the fact that they can meet the basic needs that will sustain life gains importance in this context. At this point, the most important criterion is, it is the creation of the necessary environment to meet the needs at a sufficient level. The necessity of providing this environment within the framework of living conditions is explained with the concept of "quality of life".

It is seen that the concept of quality of life has started to be discussed within the industrial revolution, The Second World War, and the ongoing urbanization problems. Over time, it is seen that the concept is supported by sustainability studies and discussed in the direction of improving the living conditions of cities in the spatial dimension. Within the scope of development policies, it is seen that the quality of life has started to take place in development studies, considering the contribution to development. Quality of life has started to be discussed within the scope of spatial dimensions as well as social and economic dimensions in different fields of study and disciplines and in the field of urban planning. 
At the point where residential areas are defined as urban and rural areas; it is known that the living conditions of rural areas are disadvantageous compared to urban areas. Low population density, barriers in physical conditions, and limited access to services cause rural areas to be less able to respond to emergencies than urban areas. Although development policies that will eliminate the disadvantaged situation of rural areas are quite common today, it is also seen that these policies are insufficient in eliminating the problems in front of the development of rural areas.

At this point, it is foreseen that there is a need for a change in the conceptual approach of rural policies and that the results of rural development will be more successful within this change. At this point, "rural quality of life", which includes rural development goals and has a multifaceted interaction with rural development as a component of development, is seen as positive developments in overcoming the obstacles in the development of rural areas. With the realization of social, economic, spatial and satisfaction-based activities aimed at increasing the quality of rural life, it is expected that the quality increase in the smallest unit of the settlements will be achieved with a bottomup multi-dimensional development model. Therefore, to increase the quality of life in rural areas, first, the current state of the quality of life should be measured.

When the quality of life measurement studies are examined spatially; it is seen that it has improved in the dimension of urban quality of life. These measurement studies are examined under two headings as qualitative and quantitative. Although the studies are common, it is seen that measurement criteria and indicators cannot be created under a common title. But it is seen that the concentrated topics mostly intersect with each other. However, quality of rural life measurement studies are seen as an area that is less than urban studies and that has not been studied in detail in the literature, and is generally examined under qualitative headings. It is seen that the quality of rural life has increased in the rate of employment in the last 10 years, and this increase also points to the importance of quality of rural life in solving current rural problems.

All developments and studies on rural areas; it can also be accepted as a prediction that change in rural areas and the dynamics that cause this change will increase and new approaches will develop. These developments are multi-faceted; these developments require innovative approaches that can accommodate the rural population in the countryside and manage to keep the rural population in the settlement. At this point, it is necessary to take actions 
that will adequately meet the living conditions of rural areas. At the beginning of all actions, a situation analysis of the quality of life in rural areas needs to be made. Situation analysis is of great importance in preparing the necessary ground for the determination of the right strategies in terms of the functional development of the development policies and the rapid progress of the solution-oriented processes. Thus, the results of each action aimed at increasing the quality of life in rural areas in the solution process and its impact on development will be foreseen.

With this study, quality of rural life studies; the contribution of these studies to rural development, which goals and dimensions of development are achieved with the content of these studies, the role of quality of life in eliminating the deficiencies in reaching the desired development in the ongoing rural development efforts, and in this direction, the necessary indicators for determining the quality of rural life should be developed. So, it is aimed to contribute to the conceptual development of the concept of rural of quality life by examining the position of the concept of rural life in national and international literature.

Within the scope of the study, urban quality of life studies that lead to spatial analysis of quality of life, documents on the measurement of quality of life of international institutions and organizations and rural quality of life studies in the literature were examined. In this context, the indicators that are mainly handled were categorized and evaluated in the context of rural development.

\section{Kaynakça/References}

Antonãn, V., Vidovićová, L. ve Figueiredo, E. (2018). Quality of rural life. Editorial 16 June 2018. European Countryside. 10, 180-190.

Başkaya, F. (2000). Kalkınma iktisadının yükselişi ve düşüşü, Ankara: İmge Kitabevi.

Bernard, J. (2018). Rural quality of life - poverty, satisfaction and opportunity deprivation in different types of rural territories. European Countryside. 10(2), 191-209.

Blekesaune, A. ve Haugen, M. (2018). Ageing in Norwegian rural and urban communities. European Countryside. 10. 232-246.

Brereton, F., Bullock, C., Clinch, JP ve Scott, M. (2011). Rural change and individual well-being: the case of Ireland and rural quality of life. European Urban and Regional Studies. 18(2), 203-227

Brambert, P. ve Kiniorska, I. (2018). Changes in the standard of living in rural population of Poland in the period of the EU membership. European Countryside. 10, 263-279. 
Casini,L., Boncinelli, F., Contini, C., Gerini, F. ve Scozzafava, G. (2018). A multicriteria approach for well-being assessment in rural areas. Social Indicators Research.

Çelik, Z. (2006). Türkiye'de kırsal planlama politikalarının geliştirilmesi. Yayımlanmamış Doktora Tezi, Dokuz Eylül Üniversitesi Fen Bilimleri Enstitüsü, İzmir.

D'Agostini, L., ve Fantini, A. (2008). Quality of life and quality of living conditions in rural areas: distinctively perceived and quantitatively distinguished. Social Indicators Research, 89(3), 487-499.

Deller, S. Tsai, T.-H., Marcouiller, D. ve English D. (2001). The role of amenities and quality of life in rural economic growth. American Journal of Agricultural Economics. 83, 352-365.

Dissart, J.C. ve Deller, S.C. (2000). Quality of life in the planning literature. Journal of Planning Literature, 15 (1), 135-161.

FAO/RAPA, (1988). Participatory monitoring and evaluation (handbook for training field workers), FAO/RAPA Publication No: 1988/2, Bangkok, Thailand.

Fischer, T. ve Born, K.M. (2018). Rural poverty and its consequences in structurally weak rural areas of Austria from the mayors' perspective. European Countryside. 10, 210-231.

Halonen, Maija ve Kattilakoski, Mari. (2018). Well-Being and participation views on policy measures in sparsely populated rural municipalities in Finland. European Countryside. 10, 300-320.

Hovardaoğlu, O. (2012). Kırsal kalkınma, yaşam kalitesi ve yakın-kırsal: Türkiye'de kırsal kalkınma stratejileri için bir kavramsal çerçeve önerisi. TÜCAUM VII. Coğrafya Sempozyumu. Ankara 288-296.

Khorasani M., Hajilo M. ve Valizadeh Z. (2015). Measurement and evaluation of quality of life components in villages of Karasf Dehestan of Khodabandeh County. Journal of Research and Rural Planning 3 (8), 65-78.

Küçükoğul, S. ve Türkoğlu, H. (2021). Kırsal yerleşmelerde yaşam kalitesinin ölçülmesi için bir yöntem önerisi: bursa köylerinden örnekler. Planlama Dergisi.31(1), 47-62

Marks-Krzyszkowska, M., ve Michalska-Żyła, A. (2018). Determinants of inhabitants' willingness to involve in co-governing rural commune. Studia Obszarów Wiejskich. 51, 99-117.

Moser, A., Peter H., Fengler, B. ve Strohm-Lömpcke, R. (2018). Improving the quality of life with rural development programmes in Germany (2007-2013): Evidence from the Evaluation. European Countryside. 10, 321-339.

Petrova, M.K., Vidovićová, L. ve Wija, P.(2018). Older adults and civic engagement in rural areas of the Czech Republic. European Countryside. 10, 247-262.

Perloff, H.S., (1969). The quality of the urban environment. Resource For The Future,Washington D.C.

Rezvani, MR ve Mansourian, H. (2011). The development of quality-of-life indicators in rural areas in Iran: case study - Khaveh Shomali district, Lorestan Province. Community Quality of Life Indicators: Best Cases. 171-191 
Tang, C., He, Y., Zhou, G., Zeng, S. ve Xiao, L. (2018). Optimizing the spatial organization of rural settlements based on life quality. Journal of Geographical Sciences. 28, 685-704

Tekeli, İ., Güler, Ç., Vazioğlu, S., Algan, N. ve Dündar, A.K. (2003). Yaşam kalitesi göstergeleri: Türkiye için bir veri sistemi önerisi. Türkiye Bilimler Akademisi Raporları,6, Ankara.

T.C. Gıda Tarım ve Hayvancılık Bakanlığı. (2015) Ulusal kırsal kalkınma stratejisi (20142020). Ankara

T.C. Kalkınma Bakanlığı. (2018). On birinci kalkınma planı (2019-2023). Kentsel Yaşam Kalitesi Özel İhtisas Komisyonu Raporu. Ankara

Türksever, N.E. (2001). Türkiye'de büyük şehir alanlarında yaşam kalitesinin değerlendirilmesine yönelik bir yöntem denemesi. Doktora Tezi, İstanbul Teknik Üniversitesi Fen Bilimleri Enstitüsü, İstanbul

United Nations Development Programme. (2020). Human development report 2020, New York: Oxford University Press.

Üçer, G. A. (2009). Kentsel yaşam kalitesinin belediye hizmetleri kapsamında belirlenmesine ve geliştirilmesine yönelik bir yaklaşım: orta ölçekli kent örnekleri, Yayımlanmamış Doktora Tezi, Gazi Üniversitesi, Fen Bilimleri Enstitüsü, Ankara.

Vaishar, A., Vidovićová, L. ve Figueiredo, E. (2018). Quality of rural life. editorial. European Countryside. 10, 180-190.

Vaznoniene, G., Kiaušienė, I. (2018). Social infrastructure services for promoting local community wellbeing in Lithuania. European Countryside. 10, 340-354.

Zarnekow, N. ve Henning, CHCA (2016). Determinants of individual quality of life ratings in rural versus suburban regions - a gender perspective. Wiest K. (der) Women and Migration in Rural Europe. 86-106 London: New Geographies of Europe. Palgrave Macmillan.

Zhou, K. (2014). Factors influencing the quality of rural human settlements in a peripheral metropolitan area based on a structural equation model: A case study from Beijing. Chinese Journal of Population Resources and Environment, 12 (4), 301-308 